\title{
Structural changes in wooden floor panels during the construction of waiting rooms for railway stations
}

\author{
Sviatoslav Volinets ${ }^{1}$, Igor Razov ${ }^{1, *}$ and Vladimir Filisuk ${ }^{1}$ \\ ${ }^{1}$ Industrial University of Tyumen, Volodarskogo str.38, Tyumen, 625001, Russia
}

\begin{abstract}
Mass migration of the urban population to the suburbs forces the producers of wooden panel houses, which are considered to be the most economical options for detached house, to constantly modify their products. Over the past 50 years, manufacturers have significantly improved the wooden panel walls. At the moment, work on improving the efficiency of such structures is in progress. However, according to the authors, the floor structure is given undeservedly little attention. In this paper, the process of testing and modifying of a standard floor slab panel, which has not changed in recent years, is described. The authors propose to increase the efficiency of the floor slab panel by adding a drop-beam, which allows not only reducing the prime cost but also to increasing the durability of the panel.
\end{abstract}

\section{Introduction}

Around the globe a lot of people are moving from cities to the suburbs. This decision is associated with more comfortable living conditions. Due to the high cost of traditional construction options for detached houses, new solutions have been developed that allow to save both money and time. One of them is the construction of houses from prefabricated wooden wall panels. Prefabricated wall structures are used in the USA, Canada, and Germany for the construction of $70 \%$ of dwellings, this quantity index in Russia has increased from 4 to $20 \%$ over the past 6 years [1].

This choice is an obvious solution for an overwhelming number of tenants. Frame wooden panel houses are cheaper in terms of materials and labor costs. The speed of construction of such houses also exceeds the speed of building houses from more traditional materials (brick, foam block). The cost of one square meter of a house made of bricks, in rough finish, in Russia is approximately 33,000 rub. (\$ 485). Therewith the construction period for a singlestorey house of 250 square meters is no less than three months. Such house also requires an expensive foundation, capable of withstanding and redistributing pressure from a heavy stone structure. In contrast, the maximum cost of one square meter of a frame wooden house does not exceed 18,000 rubles ( $\$ 265)$, and on average it costs 15,000 rubles $(\$ 220)$, which is twice as effective. With such a significant difference in price, a one story frame wooden house of 250 square meters can be built in just two weeks. In addition to obvious advantages

\footnotetext{
*Corresponding author: razovio@mail.ru
} 
in cost and speed, such structure does not require an expensive massive foundation, because the preassure transferred to the ground by a frame wooden house is about 2 times lower. [2]

Also, the obvious advantage of such houses is the constants development of the variants of the enclosing structures, that can change the cost, dimensions, materials, and other characteristics. This allows people to choose the most suitable variant of the house.

The problems of wooden panels was observed in 2011 by Ukrainchenko D.A. in his thesis. He proposed the use of glued rods to increase the crack resistance of the panel. In addition, Ukrainchenko modified the method of calculation for such structures, as a result of which the casing was included in the overall design work. With the undoubted improvement of the panels, as structures, the question of economic efficiency was considered indirectly [3]. Also, in 2011 Pyatikrestovsky K.P. considered in his thesis the Force resistance of spatial wooden structures under short-term and longterm loads, as a result of which he was able to improve the calculation for panels. The problem of the durability of wooden panels was considered in the thesis by Pyatikrestovsky, however the replacement of the material with a wooden polymer, which would significantly reduce the cost of construction, was also considered indirectly. [4]

Thus, with constant improvement of the walls, the manufacturers of frame wooden houses almost completely refused to change the floor structure. For the entire time of the existence of a frame housebuilding, the walls have become more durable and more cost efficient, while the floor structure has not changed at all. The floor slab panels used in private housing construction can also be used successfully in the construction of temporary and industrial facilities for short period staying of people. We believe that the potential of the development of floor slab panels based on a wooden frame structure is underestimated, and it is necessary to increase its economic efficiency in the same way as the efficiency of any other structure.

\section{Materials and Methods}

Initially, the frame wooden houses were built from beams and boards. Many modern manufacturers have replaced the boards with an OSB slab and the beam with a LVL beam. [5]. This solution allowed to get rid of the classic classic problems with wood:

Many modern manufacturers have replaced the boards with an OSB slab, and the beam with a LVL beam. [5] This solution allowed to get rid of the bad water resistance, shrinkage and swelling, defects, as well as to increase durability, lowering the cost. [6] This has become the goal: to reduce the cost, without reducing the durability. The base was a standard floor slab panel with IPEbeam ribbed stiffener (Fig. 1), OSB casing. The total length of the panel is $2500 \mathrm{~mm}$. Size dimension: 2500x650x262mm (Fig. 2, Fig. 3).

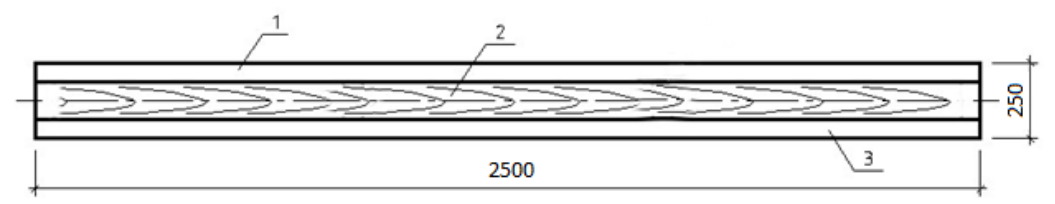

Fig. 1. The longitudinal rib of the floor slab panel.

1. top LVL flange $39 x 40 \mathrm{~mm}$.

2. OSB web $172 \mathrm{~h} 12 \mathrm{~mm}$.

3. bottom LVL flange 39x40mm. 


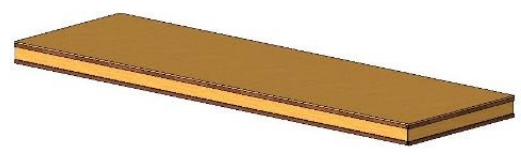

Fig. 2. General view of the panel.

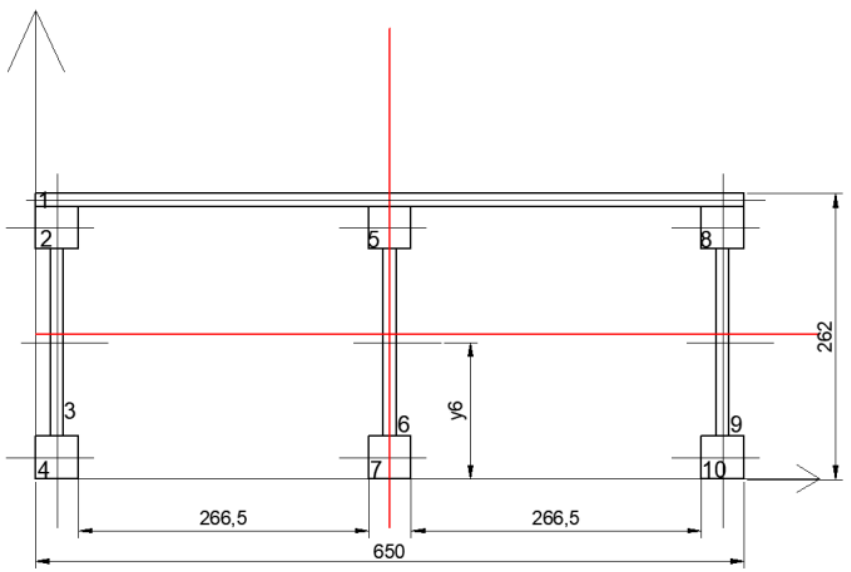

Fig. 3. Cross-section of the floor slab panel.

To determine the maximum flexural strength of this panel, tests were carried out, accord ing to all-Union State Standard 16504-81 (Figure 4).

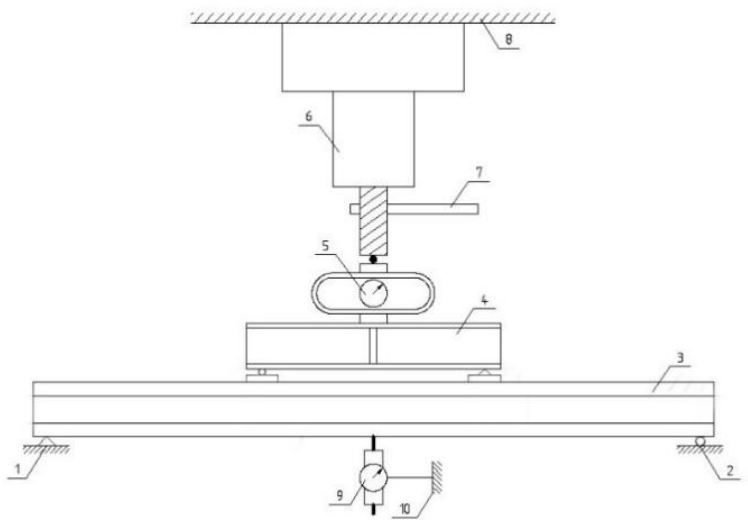

Fig. 4. Scheme of plywood panel testing with instruments and equipment.

Where: 1 - hinge fixed support;

2 - hinge-movable support;

3 - tested plywood panel;

4 - distributing steel crossarm;

5 - dynamometer with lifting capacity of 3 tons;

6 - adjustable jack;

7 - the handle of a jack;

8 - jack support;

9 - dial gauge with division value of $0.01 \mathrm{~mm}$;

10 - the holder of the dial gauge. 


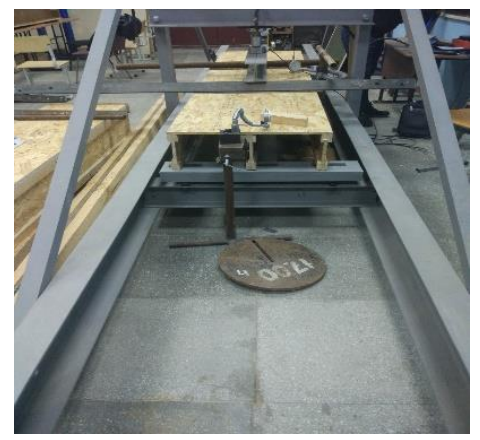

Fig. 5. General view of the panel during the test.

\section{Results}

Having analized the diagram, it is evident that the panel PP1-01 perceives loads up to $700 \mathrm{~kg}$, with a deflection of less than $2 \mathrm{~mm}$. From 700 to $2100 \mathrm{~kg}$ the deflection increases almost at the same speed, after which a loss of beam strength. Figure 6.

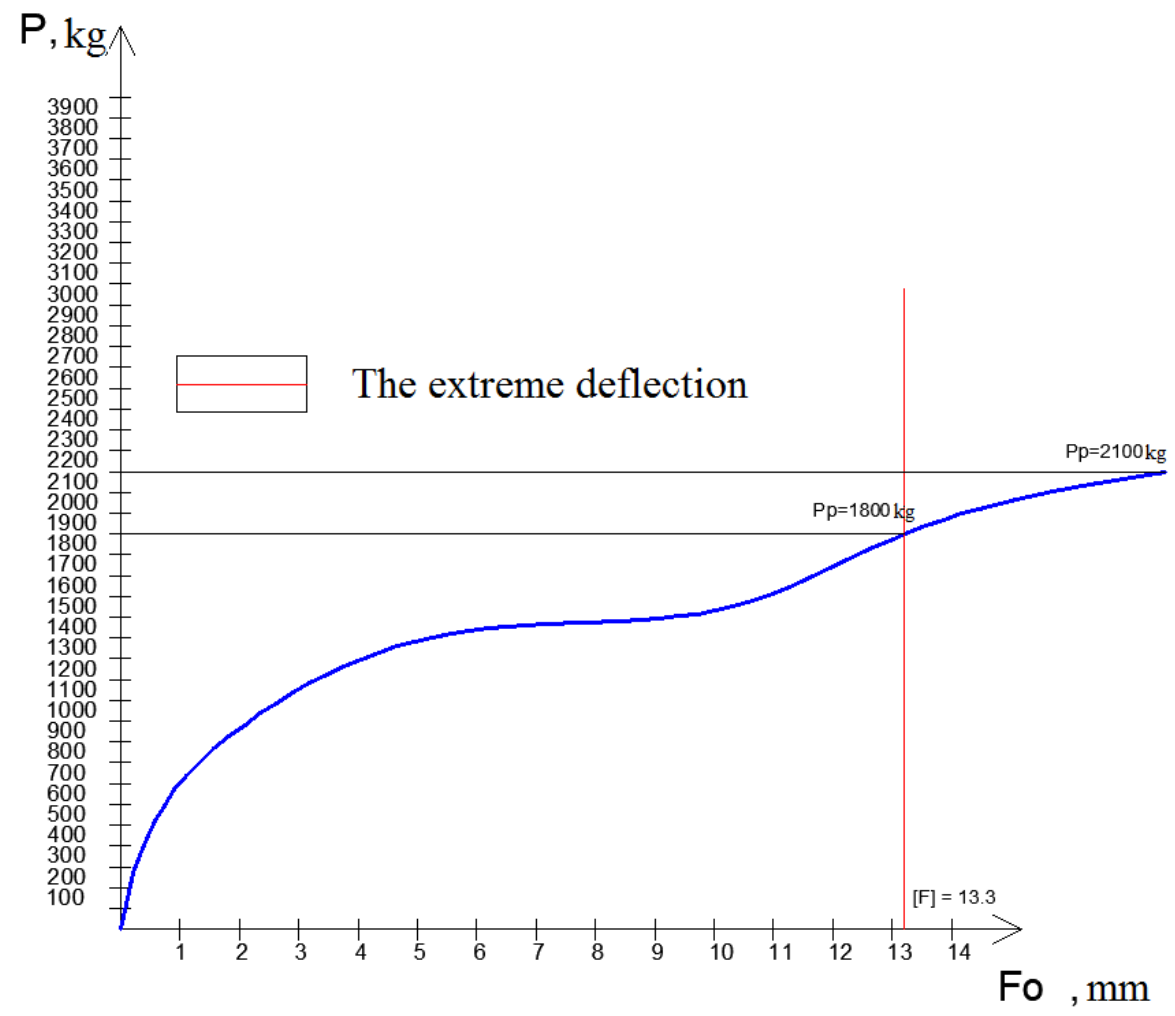

Fig. 6. Dependencies of deflection PP1-01 from the applied load.

A possible solution for cost-cutting would be a change in the geometric layout of the stiffeners. Based on the construction codes and standards SP 64.13330.2017, the maximum distance between the stiffeners for OSB casing is $50 \mathrm{~cm}$. It was necessary to find a solution 
that would allow eliminating ne stiffener, while retaining a span of less than fifty centimeters and (losing its beam strength under load of at least $2100 \mathrm{~kg}$ ).

Such solution was found, thanks to the experience of construction of wooden industrial buildings, where drop-beams were introduced to redistribute efforts from the roof to the columns, and to reduce the collapsing of the crossbars. Based on the recommendation that the drop-beam should be from 15 to $19 \%$ of the span length, the length of an OSB drop-beam was proposed to be $17 \%$ of the internal span width, so a prototype was created (Figure.4).

It is worth noting that the panel has not changed much visually (Fig. 5). The size

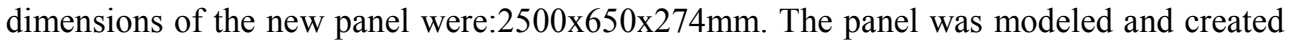
on the factory. Nags and glue were used to fasten the drop-beam.

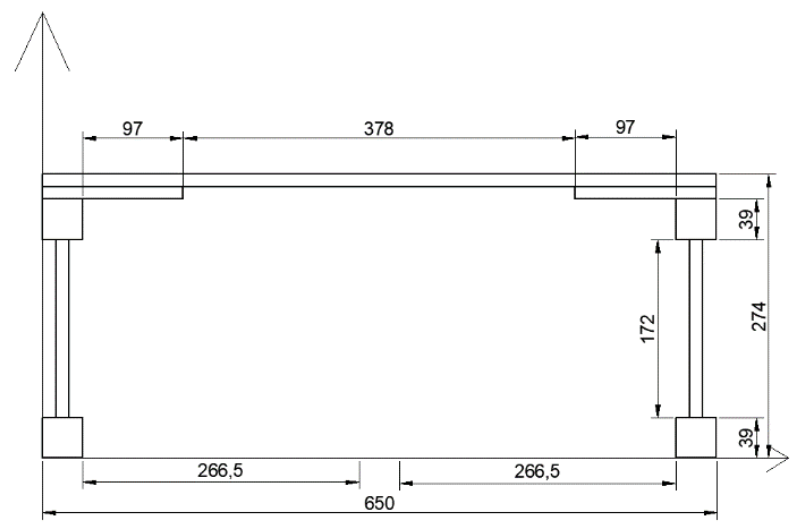

Fig. 7. Cross section of the modified floor slab panel.

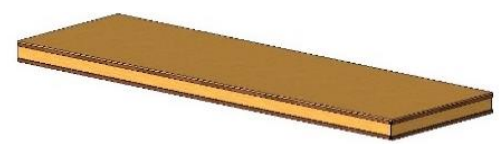

Fig. 8. General view of the modified floor slab panel.

Both panels were tested for deflection according to all-Union State Standard 16504-81. The prime cost of the panels, calculated according to average market prices for materials at thetime of May 2018, as well as the test results are given in Chart 1. For convenience, the markers PP1-01 and PPM2-01 were introduced for standard and modified panels, respectively.

Table 1. Comparison of durability characteristics and cost of panels.

\begin{tabular}{|c|c|c|c|}
\hline Panel & $\begin{array}{c}\text { Cross- } \\
\text { sectional area, } \mathrm{cm}^{2}\end{array}$ & $P_{\text {exp., }} \mathrm{cm}^{2}$ & Cost, \$ \\
\hline PP1-01 & 231,18 & 2100 & 22,31 \\
\hline PPM2-01 & 203,46 & 2250 & 17,88 \\
\hline
\end{tabular}

\section{Discussion}

From chart 1 , it can be seen that with a cost reduction of almost $20 \%$, the PPM2-01 panel under test has withstood $7 \%$ more load. Thus, one cost-cutting solution for wooden paneled floors has been found.

Arguably, according to the test results, the proposed panel is more effective than the standard sample. This allows us to state that drop-beams are effective solutions for production 
cost cutting of wooden floor structures Thanks to the identified cost-effectiveness, such panels can be used to create dismantled and restored temporary buildings and constructions on building grounds, oil fields, and to create temporary crossings.

\section{Conclusions}

We managed to create a sample of a more effective floor slab panel with a lower prime cost, and greater durability. In the future it is planned to reveal the influence of the drop-beam on the structure of the floor panel and to write some recommendations on the use of drop-beams in wooden frame floor panels.

\section{References}

1. I. Ladnykh, A. Ibragimov, International Scientific Conference on Advanced in Civil Engineering: Construction - The Formation of Living Environment, 365, 062028 (2018)

2. F. Asdrubali, B. Ferracuti, L. Lombardi, C. Guattari, L. Evangelisti, G. Grazieschi, Building and Environment 114, 307-332 (2017)

3. K.P. Piatikrestovskiy, Silovoye soprotivleniye prostranstvennykh derevyannykh konstruktsiy pri kratkovremennykh i dlitel'nykh nagruzkakh (Moscow, 2011)

4. C. Gebhardt, D. Konopka, A. Börner, M. Mäder, M. Kaliske, Journal of Cultural Heritage 29, 1-9 (2018)

5. L. M. Brenci, C. Cosereanu, O. Zeleniuc, S.V. Georgescu, A. Fotin, BioResources 13, 555-568 (2018) 